\title{
A OUVIDORIA INTERNA NO BRASIL: ONDE ESTAMOS, O QUE DESEJAMOS ${ }^{1}$
}

\section{Paulo Marzionna²}

\section{Resumo}

Este artigo apresenta o resultado de pesquisa realizada com 368 profissionais de Ouvidoria em diferentes organizações no Brasil. A pesquisa visou retratar o atual estágio das Ouvidorias no Brasil, com especial destaque para as Ouvidorias Internas e seu papel na gestão de conflitos internos às organizações. Entre os resultados obtidos, destacam-se as ferramentas mais utilizadas por Ouvidores no Brasil, identificando-se o uso mais frequente de investigações e averiguações em detrimento de outras como mediação e aconselhamento. No entanto, os resultados obtidos também sugerem que o profissional de Ouvidoria no Brasil gostaria de exercer mais atividades de mediação e menos atividades de investigação do que vem realizando hoje. As possíveis causas, consequências e caminhos para atingir esse objetivo são debatidos brevemente no fim do artigo.

Palavras-chave: Ouvidoria interna. Mediação. Investigação. Métodos alternativos de resolução de conflitos. Conflitos trabalhistas.

DOI:10.37814/2594-5068.2020v3.p35-44

1 O autor gostaria de agradecer o apoio da Associação Brasileira de Ouvidores/Ombudsman - ABO Nacional na distribuição do instrumento de pesquisa que resultou no presente artigo.

2 Doutor em Relações do Trabalho pela School of Industrial and Labor Relations, Cornell University, EUA. Professor da FGV - EAESP. (paulo.marzionna@fgv.br) 


\section{Abstract}

This article presents the results of a survey with 368 Ombudsmen in different organizations in Brazil. This research project tried to depict the current stage of the Ombudsman Offices in Brazil, with special emphasis on Internal Ombudsmen and their role in conflict management in organizations. Among the results obtained, it should be highlighted the conflict management methods more used by Ombudsmen in Brazil, as results suggest that investigation is used more frequently than mediation and coaching techniques. However, the results also suggest that Ombudsmen in Brazil would be interested in using more mediation techniques, instead of the current dominant investigation strategies. The possible causes, consequences and paths for achieving this desired result are briefly discussed in the end of this article.

Keywords: Internal organizational Ombudsman. Employment mediation. Alternative dispute resolution methods. Workplace conflicts. 


\section{INTRODUÇÃO}

É notório que a Reforma Trabalhista de 2017 (Lei 13.467/2017) teve como um de seus objetivos expressos diminuir o nível de conflitos no ambiente de trabalho brasileiro - seja por meio da valorização da negociação individual e coletiva, seja por meio de mudanças em regras processuais trabalhistas, conforme evidenciado pela tramitação do projeto de lei na Câmara e no Senado. Até o momento, no entanto, os únicos resultados mensuráveis dizem respeito à redução do nível de litigiosidade trabalhista (CESTP, 2019).

Estes números, no entanto, não podem ser interpretados para além do nível de litigiosidade não seria recomendável interpretá-los como evidência de que, de fato, houve uma diminuição no nível de conflitos nos ambientes de trabalho do País. Pelo contrário, servem apenas de evidência de que eventuais conflitos trabalhistas não estão sendo mais levados para o Judiciário, sendo potencialmente tratados por outros métodos quando surgem. Em outra oportunidade, manifestamo-nos no sentido de que a Reforma Trabalhista poderia incentivar a adoção de métodos alternativos de resolução de conflitos, tais como a arbitragem, expressamente prevista no texto da Reforma, além da mediação e Ouvidorias Internas (MARZIONNA, 2018).

Dentro desses métodos, o presente artigo visa explorar o papel efetivamente exercido por Ouvidorias na gestão de conflitos no ambiente de trabalho brasileiro, a partir de dados primários obtidos por instrumento de pesquisa respondido por Ouvidores brasileiros de diversos setores.

\section{O CENÁRIO BRASILEIRO: MÉTODOS DE GESTÃO DE CONFLITOS E O PAPEL DAS OUVIDORIAS}

Embora o tema de gestão de conflitos no ambiente de trabalho e a adoção de diferentes métodos por organizações seja extensamente estudado nos EUA (ex.: LIPSKY, SEEBER; FINCHER, 2003; STIPANOWICH; LAMARE, 2014), no Brasil o debate sobre o tópico ainda é incipiente. Entretanto, o escasso material ora disponível já sugere que Ouvidorias exercem um papel importantíssimo na gestão de conflitos no ambiente de trabalho em organizações brasileiras. Por exemplo, a revista Você S/A informa que Ouvidorias estavam presentes em 112 das 150 empresas que faziam parte do ranking de 2010 das melhores empresas para se trabalhar e que tais canais são centrais no combate ao assédio moral nessas organizações (INOHARA, 2013). Na mesma direção, pesquisa patrocinada pela Associação Brasileira de Recursos Humanos - ABRH também identificou algumas tendências quanto aos métodos utilizados para gestão de conflitos no ambiente de trabalho brasileiro. A pesquisa, respondida por representantes de 136 empresas, apontou que a mediação gerencial é o mecanismo mais popular de gestão interna de conflitos, adotada por pouco mais de $75 \%$ das organizações, seguida pela mediação com recursos internos, adotada por pouco mais de $60 \%$ das organizações. Os "canais internos para colaboradores, Ouvidoria Interna ou Ombudsman" foram apontados como utilizados por quase $30 \%$ dos respondentes (LEVY et al., 2016).

Como já mencionado anteriormente (MARZIONNA, 2018), é essencial que se tenha cautela ao analisar esses números sobre Ouvidorias como canais de gestão de conflitos internos organi- 
zacionais, já que não há clareza sobre como cada empresa ou instituição efetivamente organiza e utiliza sua Ouvidoria. Destaque-se que essas possíveis diferenças são relevantes não só por mera curiosidade acadêmica, já que há sugestões de que diferentes estruturas e regras de funcionamento podem impactar resultados e utilizações de diferentes sistemas de Ouvidoria Interna (MARZIONNA, 2016).

É justamente neste contexto que se buscou obter maior clareza sobre o atual e efetivo estágio e papel das Ouvidorias brasileiras no que diz respeito a conflitos internos das organizações - ou seja, conflitos de natureza trabalhista.

\section{METODOLOGIA - O INSTRUMENTO DE PESQUISA}

O instrumento de pesquisa utilizado foi um questionário elaborado pelo próprio autor em 2018, composto por 48 perguntas, entre questões de múltipla escolha e questões abertas, e que seriam respondidas por profissionais de Ouvidoria de todo o Brasil. As 48 questões abarcavam temas como dados da instituição do respondente, informações sobre histórico, funcionamento e organização da Ouvidoria na instituição, informações sobre a formação e histórico do Ouvidor ou profissional responsável pela Ouvidoria na instituição, bem como a opinião do respondente sobre afirmações relativas ao papel ideal da Ouvidoria em organizações brasileiras. Não foram coletadas quaisquer informações identificadoras sobre o respondente ou sua organização ${ }^{3}$.

O questionário foi validado com representantes da Associação Brasileira de Ouvidores/Ombudsman (ABO-Nacional). O instrumento foi distribuído por meio de e-mail, link na página de internet e página de Facebook para todos os membros da ABO-Nacional. Além disso, membros da ABO-Nacional também divulgaram entre seus contatos link para o instrumento de pesquisa por meio de grupos de Facebook, Linkedln e WhatsApp envolvendo Ouvidores em todo o Brasil.

O instrumento de pesquisa foi aplicado por meio do sistema Qualtrics, disponibilizado pela Universidade de Cornell (EUA), e ficou aberto para recebimento de respostas entre os dias 25 de março de 2018 e 25 de maio de 2018. Um total de 368 respostas válidas foram obtidas, embora nem todos os respondentes tenham concluído o questionário ${ }^{4}$. $\mathrm{Na}$ análise abaixo são consideradas apenas as respostas com informações suficientes para a análise do ponto em debate.

A análise das respostas foi feita com a utilização do Microsoft Excel e da linguagem de programação R.

\section{RESULTADOS}

O objetivo desta seção não é listar a totalidade dos resultados obtidos, mas destacar os pontos mais importantes para uma adequada descrição da condição das Ouvidorias no Brasil no que diz

30 instrumento de pesquisa está disponível para consulta mediante contato por e-mail com o autor do artigo.

4 Consideraram-se válidas apenas as respostas que incluíram a informação sobre a existência ou não de "Ouvidoria Interna" na organização do respondente.

38 | Revista Científica da Associação Brasileira de Ouvidores/Ombudsman - Ano 3 - n $3-2020$ 
respeito à gestão de conflitos internos/trabalhistas e análise dos potenciais próximos passos que essa ferramenta deve seguir no Brasil ao longo dos próximos anos.

\subsection{Presença da Ouvidoria}

A primeira informação relevante trazida pela pesquisa diz respeito à efetiva popularidade da Ouvidoria Interna entre organizações brasileiras. Destaque-se que, no instrumento de pesquisa, Ouvidoria Interna foi assim definida: "Ouvidoria voltada para o atendimento do público interno da organização (ex.: empregados, funcionários, colaboradores, gestores etc.), mesmo que estas atividades não possuam nomenclatura ou estrutura separada". Ouvidoria Externa, por sua vez, foi definida como: "Ouvidoria voltada para o atendimento do público externo da organização (ex.: clientes, cidadãos, fornecedores etc.)".

Tanto no setor público quanto no setor privado, mais da metade das organizações que possuem Ouvidoria Externa também possuem Ouvidoria voltada para o público interno. Entre as organizações da Administração Pública (secretarias, órgãos, autarquias, universidades públicas), $89,4 \%$ possuem Ouvidoria Interna e, entre empresas privadas, 65,5\% contam com ela. É importante frisar que esses dados não sugerem que a maioria das organizações brasileiras possui Ouvidoria Interna - apenas que, entre as organizações que possuem algum tipo de Ouvidoria (geralmente, Ouvidoria Externa), a Ouvidoria também se dedica a assuntos internos da organização na maioria absoluta dos casos. A razão da predominância no setor da Administração Pública deve ser objeto de pesquisa futura.

Entre os segmentos das organizações avaliadas, merece destaque a maciça presença de Ouvidorias Internas em alguns segmentos específicos, como Educação (92,5\% dos respondentes possuem Ouvidoria Interna), Saúde e Serviços Sociais $(77,5 \%$ dos respondentes possuem Ouvidoria Interna) e Serviços Financeiros e Bancários (69,6\% dos respondentes possuem Ouvidoria Interna). Por outro lado, no setor de Transporte, incluindo concessionárias de metrô, estradas e aeroportos, a maioria dos respondentes não possui Ouvidoria Interna (35,7\%). Informações sobre outros setores devem ser encaradas com cautela, em face da baixa amostragem setorial.

No que diz respeito à eventual relação entre o tamanho da organização e a presença de Ouvidoria Interna, a expectativa era no sentido de que grandes organizações tivessem Ouvidorias Internas mais frequentemente que organizações menores. Tal expectativa foi confirmada, na medida em que $73,2 \%$ das organizações com menos de 500 empregados possuem Ouvidoria Interna, enquanto $90,9 \%$ das organizações com mais de 10 mil empregados possuem Ouvidoria Interna. Tais resultados não surpreendem, tendo em vista que acreditamos que a presença de Ouvidoria Interna pode estar diretamente relacionada à ocorrência maior de conflitos no ambiente de trabalho, o que, naturalmente, tende a se observar em organizações com maior número de empregados.

É válido também salientar a estrutura das Ouvidorias nas organizações estudadas. Das 350 organizações com Ouvidoria Externa, 78,6\% possuem também uma Ouvidoria Interna. Apenas 13 respondentes (3,5\% do total) possuem Ouvidoria Interna, mas não possuem Ouvidoria Externa. Frise-se que a existência de Ouvidoria Interna na organização não significa que ela possui estru- 
tura própria e independente da Ouvidoria Externa. Em 91,7\% dos casos em que ambos os tipos de Ouvidoria estão presentes, a estrutura é compartilhada pelas duas Ouvidorias.

\subsection{Funcionamento das Ouvidorias}

As informações acima fornecem um retrato geral da presença de Ouvidorias Internas nas organizações dos respondentes e como elas se relacionam a setores específicos ou ao tamanho da organização. Os resultados a seguir, no entanto, vão além, buscando identificar padrões e informações relevantes quanto ao efetivo funcionamento dessas Ouvidorias Internas.

Com relação aos canais de acesso disponíveis para empregados e colaboradores que desejam utilizar a Ouvidoria Interna, a possibilidade de Atendimento Presencial é oferecida pela vasta maioria das organizações, seguida de perto pela possibilidade de utilização de e-mail, sistema informatizado (internet/intranet), ou telefone. O canal Caixa Postal/correspondência é oferecido hoje por pouco mais de metade das organizações, enquanto a utilização de redes sociais ainda é incipiente. O Gráfico 1 detalha essas informações.

\section{GRÁFICO 1 - Canais de acesso disponíveis ${ }^{5}$}

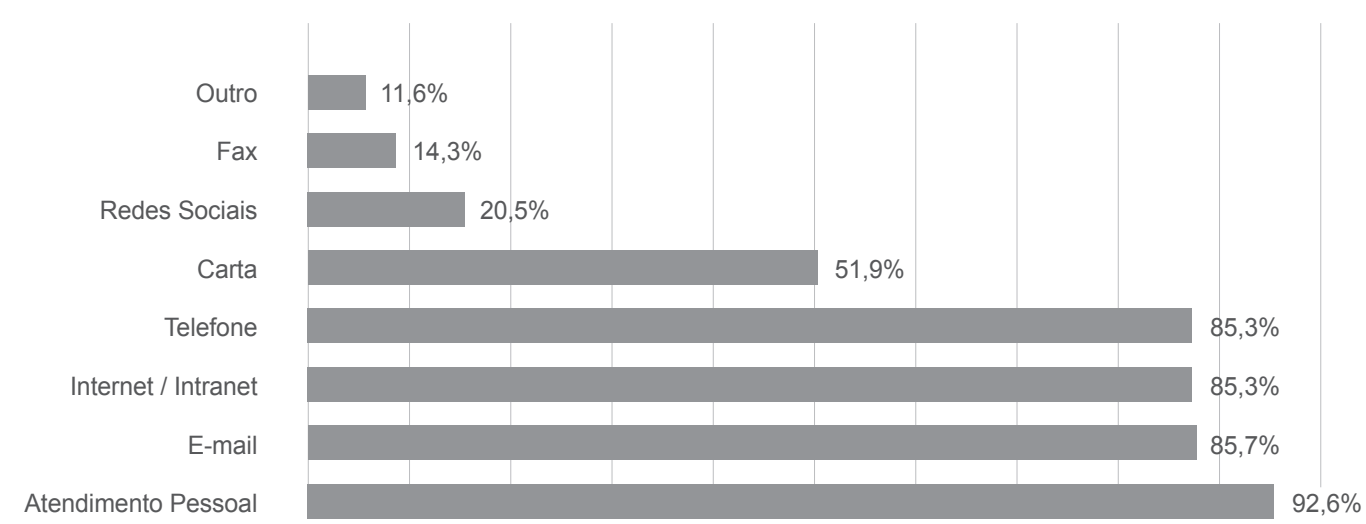

É importante frisar que o Gráfico 1 apresenta apenas os canais disponíveis, mas não reflete sua efetiva utilização para casos de Ouvidoria Interna. A pesquisa solicitou que os respondentes estimassem o percentual total de casos envolvendo questões de Ouvidoria Interna que chegavam à Ouvidoria por meio de cada um dos canais de acesso. A realidade obtida é bastante diferente, como revela o Gráfico 2, que detalha a média de efetiva utilização de cada canal de acesso nas Ouvidorias das organizações dos respondentes. Como se observa, sistemas informatizados são aqueles mais usualmente utilizados. Já canais como cartas/caixa postal, embora ainda presentes em 51,9\% das Ouvidorias, possuem um nível de utilização bastante reduzido (média de 5,9\%).

5 Os respondentes foram instados a responder sobre canais para casos de Ouvidoria Interna, quando possível. No entanto, em função das estruturas compartilhadas, é impossível separar em muitos casos o que se refere à Ouvidoria Interna ou à Externa. 


\section{GRÁFICO 2 - Média de utilização efetiva dos canais de acesso ${ }^{6}$}

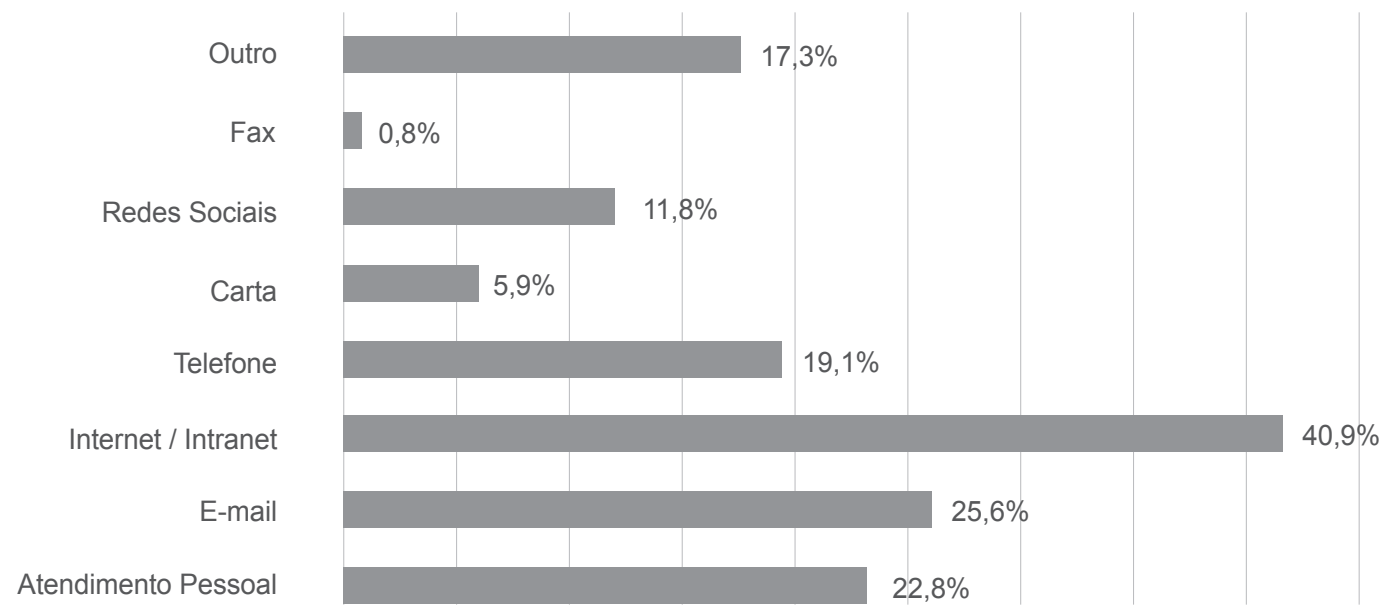

Um fator de grande importância para a percepção de independência das Ouvidorias Internas diz respeito à possibilidade de apresentação de denúncia anônima, de modo a preservar a identidade do empregado eventualmente envolvido em um conflito no ambiente de trabalho. Nesse sentido, o notável é que $82,1 \%$ dos respondentes afirmaram que em suas organizações há a possibilidade de que a denúncia para a Ouvidoria Interna seja feita de maneira anônima. Apesar disso, é importante notar que, em média, apenas $34,2 \%$ dos casos relativos à Ouvidoria Interna são de fato protocolados de maneira anônima no sistema de cada organização.

Os respondentes também foram instados a estimar o percentual relativo a cada tipo de caso que chega ao canal de Ouvidoria Interna de suas organizações. Nesse contexto, alguns números merecem destaque: embora casos de assédio moral sejam qualitativamente relevantes, eles representam, em média, apenas $7 \%$ dos casos apresentados; questões e dúvidas representam em média $27,1 \%$ de todas as manifestações que chegam a esses canais; reclamações, tanto de infraestrutura, políticas e ferramentas, quanto de questões pontuais de gestão, representam em média $24 \%$ de todos os casos recebidos pelas Ouvidorias Internas.

\subsection{O tratamento dado aos casos recebidos}

Os dados acima são importantes para se entender quais casos chegam às Ouvidorias Internas e o canal de acesso utilizado, mas pouco dizem quanto ao que é feito desses casos, uma vez recebidos pela Ouvidoria Interna. Nesse sentido, a pesquisa pediu para que cada respondente informasse com que frequência sua Ouvidoria conduzia as seguintes atividades: investigação/averiguação (i.e., checagem dos fatos descritos, conduzida pela própria Ouvidoria); mediação; aconselhamento/

6 Os respondentes foram instados a responder sobre a utilização dos canais de acesso para casos de Ouvidoria Interna, quando possível. No entanto, em função das estruturas compartilhadas, é impossível separar em muitos casos o que se refere a Ouvidoria Interna e Externa. 
coaching; orientação para o gestor do denunciado; e encaminhamento do assunto a outra área, para ciência e tomada de providências. O Gráfico 3 apresenta um resumo das respostas. Alguns resultados merecem destaque. Primeiramente, é notável o alto nível de utilização de investigação/ averiguação, com $45 \%$ dos respondentes informando usá-la frequentemente ou sempre, resultado semelhante ao do encaminhamento do caso para outro departamento para providências. É importante frisar, ainda, que $25 \%$ dos respondentes informaram que a mediação nunca é utilizada, e $27 \%$ informaram que aconselhamento/coaching jamais é utilizado. Tais pontos serão debatidos mais profundamente na próxima seção deste artigo.

\section{GRÁFICO 3 - Frequência de utilização de cada resposta}

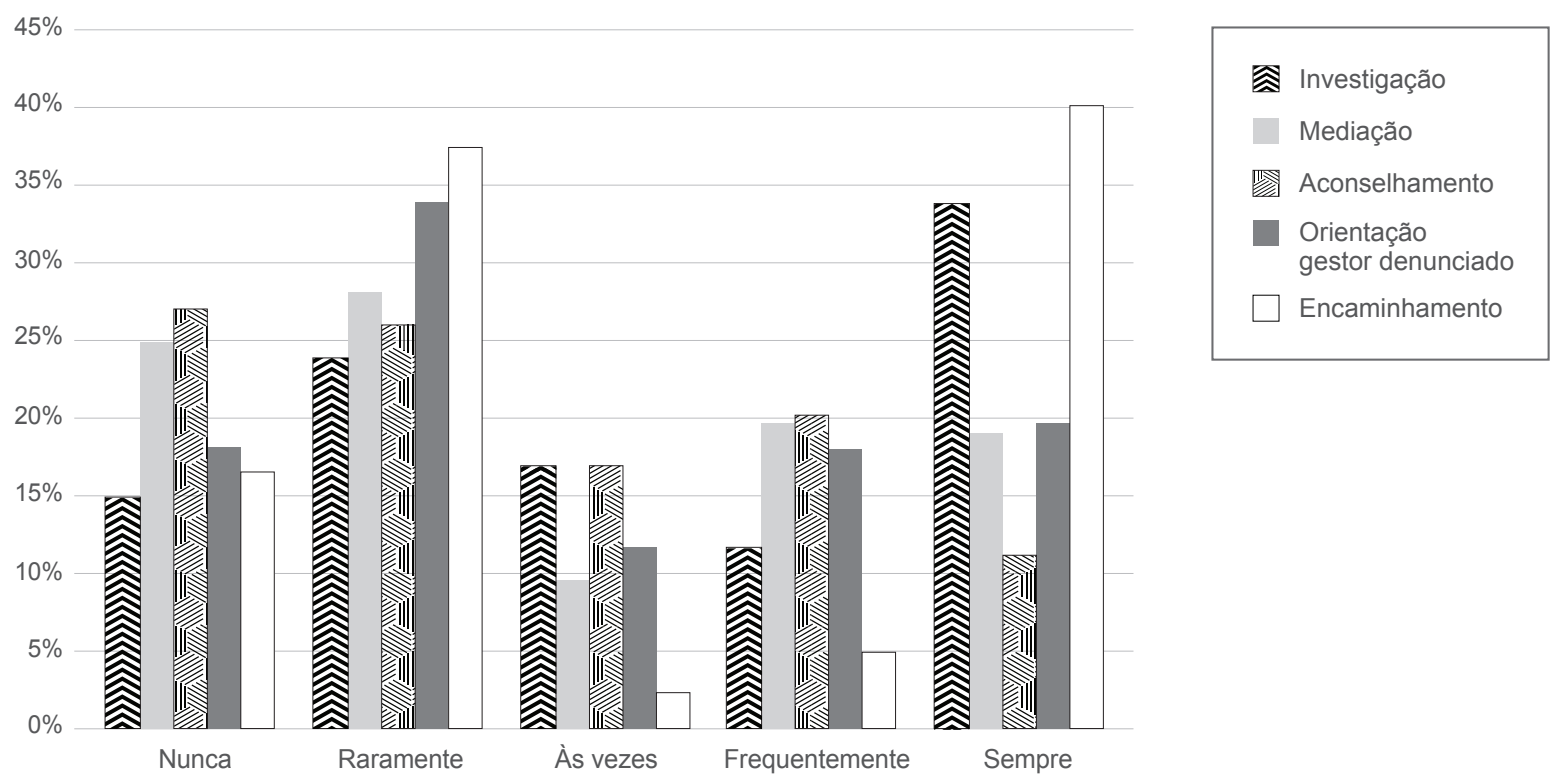

Comumente, indica-se que o nível de independência de uma Ouvidoria Interna é essencial para a consecução de seus objetivos (ROWE; GADLIN, 2014). Nesse sentido, é importante destacar que $64 \%$ dos respondentes consideraram que a Ouvidoria Interna em suas organizações possui considerável ou total independência para tomar a decisão sobre como tratar o caso e definir quais as providências a serem tomadas. De igual modo, $78 \%$ dos respondentes afirmaram que a Ouvidoria Interna em suas organizações possui razoável ou total acesso a dados, documentos e registros necessários para o tratamento dos casos.

\subsection{A Ouvidoria desejada}

Se até o momento tem sido traçado um retrato da atual situação das Ouvidorias Internas, esta seção se encerra com a visão dos respondentes sobre o que eles acreditam que deva ser o papel da Ouvidoria Interna no futuro de suas respectivas organizações ou em um cenário ideal. Para tan- 
to, os respondentes foram instados a avaliar algumas afirmações sobre o papel da Ouvidoria Interna. Com relação à afirmação de que a principal função da Ouvidoria Interna deveria ser conduzir investigações, a posição dos respondentes foi bastante dividida, com $50 \%$ discordando total ou parcialmente da afirmação e $43 \%$ concordando total ou parcialmente com ela. Diante da afirmação de que cabe ao Ouvidor ser o mediador dentro da organização, 91\% dos respondentes disseram concordar total ou parcialmente com ela. Por fim, apresentados à afirmação de que, sempre que possível, a Ouvidoria Interna deveria buscar a mediação em vez de outros mecanismos de resolução de conflitos, 93\% dos respondentes informaram concordar com ela.

\section{Análise e Discussão}

Os dados apresentados na seção acima são importantíssimos por traçarem um primeiro retrato completo sobre as Ouvidorias brasileiras, notadamente no que diz respeito à sua utilização como canal de gestão de conflitos internos às organizações, públicas ou privadas.

Apesar da importância dos dados apresentados, é essencial que se tenha em mente algumas limitações da pesquisa. Primeiramente, é fundamental que se compreenda que essa pesquisa não visa identificar qualquer informação sobre a presença geral de Ouvidorias em organizações brasileiras, uma vez que a amostra de respondentes é constituída, justamente, por organizações que já possuem Ouvidorias - internas ou externas. Ademais, embora o foco sejam as Ouvidorias Internas, há uma significativa dificuldade para se diferenciar alguns dos resultados descritos entre Ouvidorias internas e externas - possivelmente em função da estrutura compartilhada entre ambos os tipos de Ouvidoria, como descrito anteriormente.

Feitas essas considerações, algumas importantes discussões podem ser iniciadas com base nos resultados acima apresentados. Neste artigo, optamos por focar no papel atualmente exercido pelas Ouvidorias Internas e aquilo que os Ouvidores efetivamente vislumbram como sua função em suas organizações.

A literatura internacional geralmente vê Ouvidorias exercendo um papel de facilitadoras na gestão de conflitos dentro das organizações, eventualmente assumindo o papel de mediadoras, coach e conselheiras na gestão de diversos tipos de conflitos em organizações. Não raro, Ouvidorias são apontadas como detentoras de um papel central de protagonismo em Sistemas Integrados de Gestão de Conflitos. Nesses casos, parece haver um consenso sobre o fato de que não é papel da Ouvidoria conduzir investigações sobre os casos que chegam a ela, sob pena de ver sua independência e imparcialidade em xeque perante seus potenciais usuários (ROWE; GADLIN, 2014).

Neste contexto, é interessante notar como investigações e averiguações são usadas sempre ou frequentemente por $45 \%$ das Ouvidorias, enquanto mediação e aconselhamento nunca são utilizados, respectivamente, por $25 \%$ e $27 \%$ de todos os respondentes. Embora seja possível debater se as investigações a que se referem essas respostas podem realmente ser consideradas investigações do ponto de vista formal (em oposição à simples checagem superficial dos fatos alegados), é notável a diferença em seu nível de utilização em comparação com os métodos de mediação e aconselhamento. 
Ainda mais relevante é a comparação destes dados com aquilo que os Ouvidores entrevistados afirmam desejar para a Ouvidoria, já que mais de $90 \%$ dos respondentes concordaram com afirmações no sentido de que a mediação deveria ser o método preferencial das Ouvidorias Internas, exercendo o Ouvidor o papel de principal mediador dentro da organização.

Mais do que revelar um descompasso entre a atual Ouvidoria Interna e aquilo que desejam os Ouvidores, os resultados acima sugerem que há um caminho importante para se explorar na construção da Ouvidoria Interna como líder na adoção de técnicas de mediação nas mais diversas organizações brasileiras. Para tanto, é inegável o papel que associações e organizações de Ouvidores podem desempenhar na capacitação de profissionais de Ouvidoria no campo da mediação, assim como o papel essencial a ser exercido por Ouvidores como transformadores da cultura de gestão de conflitos em suas organizações.

\section{Pesquisa futura}

A discussão acima aborda apenas um dos possíveis debates levantados pelos resultados da pesquisa ora apresentados. Os resultados acima, bem como outros ainda a serem divulgados, permitem que se iniciem importantes discussões sobre o atual retrato das Ouvidorias Internas brasileiras, seu funcionamento e estrutura, bem como o potencial de diversos papéis que Ouvidorias e Ouvidores ainda podem exercer nas mais diversas organizações brasileiras. Além disso, é importante que pesquisas sobre o papel, estrutura e funcionamento de Ouvidorias Internas não se encerrem no questionário conduzido em 2018. Idealmente, novas pesquisas devem se dar nos próximos anos, de modo a identificar tendências e transformações nas Ouvidorias brasileiras.

\section{REFERÊNCIAS}

Coordenadoria de Estatística e Pesquisa do TST - CESTP. Recebidos e Julgados da JT. Disponível em: http://www. tst.jus.br/web/estatistica/jt/recebidos-e-julgados. Acesso em: 30 jun. 2019.

INOHARA, A. O 0800 explode no combate ao assédio moral. Exame - Você S/A. 28 nov. 2013. Disponível em: <https://exame.abril.com.br/carreira/a-explosao-do-0800/2/>. Acesso em: 28 maio 2018.

LEVY, F.; BURBRIDGE, M.; FREIRE, M.; SILVA, T. O Papel do RH na Gestão de Conflitos Organizacionais. ABRH-SP - Associação Brasileira de Recursos Humanos. 2016. Disponível em: <https://abrhsp.org.br/wp-content/ uploads/2018/03/resultado_rh_resolucao_2016.pdf>. Acesso em: 28 maio 2018.

LIPSKY, D. B.; SEEBER, R. L.; FINCHER, R. Emerging Systems for Managing Workplace Conflict. 1. ed. San Francisco, CA: Josey Bass, 2003.

MARZIONNA, P. Complaining to the Ombudsman: alternative dispute resolution in the Brazilian workplace. 2016. Dissertação (Mestrado em Relações do Trabalho) - School of Industrial and Labor Relations, Cornell University, Ithaca, NY, EUA.

. Ouvidorias e conflitos no ambiente de trabalho: caminhos para pesquisa e prática. Revista Científica da Associação Brasileira de Ouvidores/Ombudsman, 2, 2018, p. 85-95.

ROWE, M.; GADLIN, H. The Organizational Ombudsman. In: ROCHE, W. K.; TEAGUE, P.; COLVIN, A. J. (Eds.). The Oxford handbook of conflict management in organizations. Oxford University Press, 2014.

STIPANOWICH, T. J.; LAMARE, J. R. Living with ADR: Evolving Perceptions and Use of Mediation, Arbitration, and Conflict Management in Fortune 1000 Corporations. 19 Harvard Negotiation Law Review, 1, 2014. 